\title{
Study on Seismic Control of Power Transmission Tower-Line Coupled System under Multicomponent Excitations
}

\author{
Li Tian, Qiqi Yu, and Ruisheng Ma \\ School of Civil and Hydraulic Engineering, Shandong University, No. 17922 Jingshi Road, Lixia District, Jinan, Shandong 250061, China \\ Correspondence should be addressed to Li Tian; tianli@sdu.edu.cn
}

Received 29 July 2013; Accepted 27 August 2013

Academic Editor: Hong-Nan Li

Copyright ( 2013 Li Tian et al. This is an open access article distributed under the Creative Commons Attribution License, which permits unrestricted use, distribution, and reproduction in any medium, provided the original work is properly cited.

\begin{abstract}
The seismic control of power transmission tower-line coupled system subjected to multicomponent excitations is studied in this paper. The schematic of tuned mass damper is introduced, and equations of motion of a system with tuned mass damper under multi-component excitations are proposed. Three-dimensional finite tower-line system models are created based on practical engineering in studying the response of this system without and with control. The time domain analysis takes into account geometric nonlinearity due to finite deformation. The optimal design of the transmission tower-line system with tuned mass damper is obtained according to different mass ratio. The effects of wave travel, coherency loss, and different site conditions on the system without and with control are investigated, respectively.
\end{abstract}

\section{Introduction}

Power transmission tower-line system is an important facility of a power system. Its failure may lead to the outage of power supply [1]. The transmission tower is usually designed by static load, impulsive load, wind loads, ice load, and so forth. However, most transmission lines need cross high seismic intensity zone in China, and many towers and lines were damaged in past earthquakes. In the 1976 Tangshan earthquake, some towers were collapsed [2]. During the 1995 Kobe earthquake, 38 transmission lines were damaged, and 20 towers were tilted as a result of foundation settlement [3]. During the 1999 Chi-Chi earthquake, many lines were broken, and some towers collapsed [4]. In the 2008 Wenchuan earthquake, Sichuan electric network was damaged seriously [5]. Electric systems were damaged during the 2013 Yaan earthquake in China. Some pictures of damaged towers and lines are shown in Figure 1.

A few foreign and domestic researchers have studied the vibration control of transmission tower-line system in recent years. Battista et al. [6] envisaged nonlinear pendulum-like damper (NLPD) installed on the tower in order to reduce the displacement at the top of tower, and the efficiency of nonlinear pendulum-like damper was demonstrated. Huang and Tang [7] researched the vibration control effect of tuned liquid damper (TLD) based on large span transmission tower. Chen and Tang [8] investigated the vibration control effect of the multiple tuned mass dampers (MTMD) and viscoelastic damper (VED) under wind excitation based on Jiangyin Yangtze River $500 \mathrm{kV}$ long span transmission line. Deng et al. [9] studied wind vibration control experiment based on $500 \mathrm{kV}$ Jiangyin large span tower and verified the design program of tuned mass damper (TMD) and viscoelastic dissipater (VED). Liu and $\mathrm{Li}[10]$ presented a method to simulate tuned mass damper (TMD) and analyzed the control of wind-induced dynamic response for transmission towerline system. In all these studies, the vibration controls of transmission towers under wind excitation were carried out, but the research about earthquake control of transmission tower-line system is very little.

To date, the seismic control of power transmission towerline system under multicomponent excitations has not been investigated. In this paper, the schematic of TMD is introduced, and equations of motion of a system with TMD under seismic excitation are proposed. Three-dimensional finite tower-line system models are considered in studying 


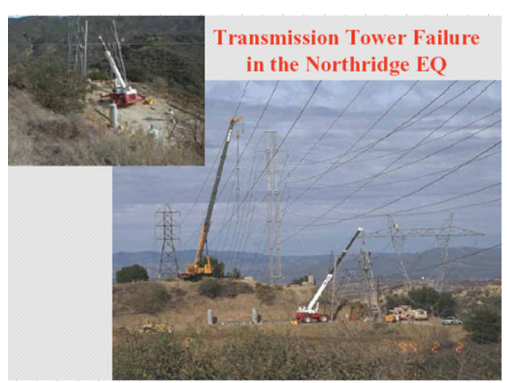

(a)

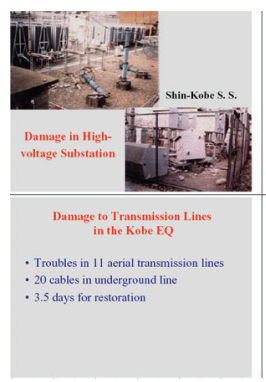

(b)

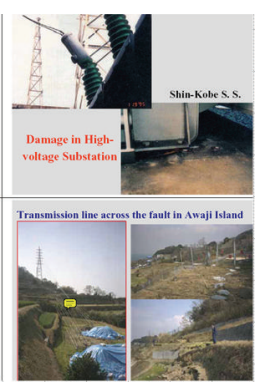

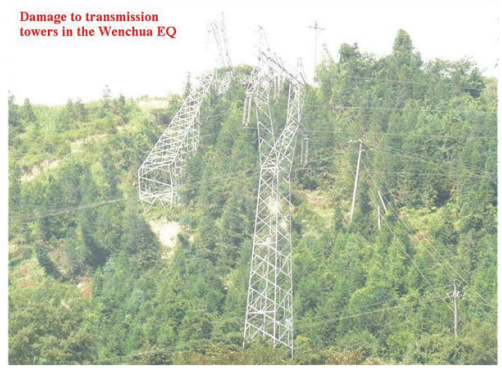

(c)

FIGURE 1: Damage to transmission tower-line system in the earthquake.

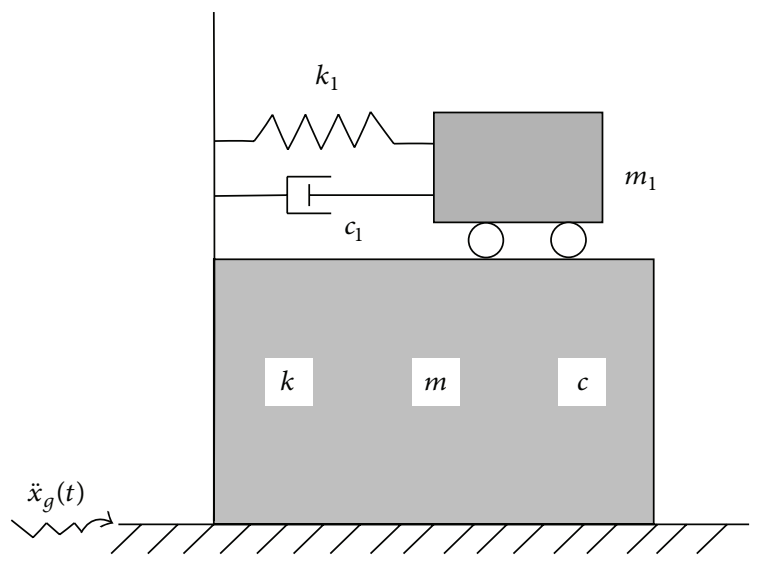

FIgURE 2: Schematic structure with tuned mass damper.

the response of this system without and with control. The transmission towers are modeled by beam elements, while the transmission line is modeled by cable elements that account for the nonlinear geometry of the transmission lines. The time domain analysis takes into account geometric nonlinearity due to finite deformation. The optimal design of the transmission tower-line system with TMD is obtained according to different mass ratio. The transmission towerline system is the difference among the ground motion components affecting various support points of the structure. The parameters studied include the effect of wave passage, coherency loss, and different local site.

\section{Equations of Motion of a System with TMD}

2.1. Schematic of TMD. A tuned mass damper (TMD) is a dynamic absorber consisting of a mass, spring, and damping [11]. If the structure is simplified as a single-degree-offreedom system, the reducing vibration calculation model of the structure with TMD system is shown in Figure 2. Tuned mass damper-structure reducing vibration system is that the tuned mass damper install in the structure.

The equation of motion of tuned mass damper can be written as

$$
m_{1} \ddot{x}_{1}+c_{1} \dot{x}_{1}+k_{1} x_{1}=-m_{1} \ddot{x}-m_{1} \ddot{x}_{g}(t)
$$

where $x_{1}$ is the displacement of tuned mass damper, $x$ is the displacement of structure, $m_{1}, c_{1}$, and $k_{1}$ are the mass, damping, and stiffness of tuned mass damper, respectively.

The equation of motion of structure with TMD can be expressed as

$$
m \ddot{x}+c \dot{x}+k x=-m \ddot{x}_{g}(t)+c_{1} \dot{x}_{1}+k_{1} x_{1},
$$

where $m, c$, and $k$ are the mass, damping, and stiffness of structure, respectively, and $\ddot{x}_{g}(t)$ is the input seismic wave.

\subsection{Equation of Motion of a System with TMD under Seismic} Excitation. If a tuned mass damper is fixed on the tower under seismic excitation, then the equation of motion of the structure with TMD control can be expressed as

$$
\begin{gathered}
\mathbf{M} \ddot{\mathbf{x}}+\mathbf{C} \dot{x}+\mathbf{K} x-\{E\}\left(c_{t} \dot{x}_{t}+k_{t} x_{t}\right)=-\mathbf{M} \ddot{u}_{g}, \\
m_{t}\left(\ddot{x}_{t}+E^{T} \ddot{x}\right)+c_{t} \dot{x}_{t}+k_{t} x_{t}=0,
\end{gathered}
$$

where $M, C$, and $K$ are the mass, damping, and stiffness matrix of tower structure, respectively; $x, \dot{x}$, and $\ddot{x}$ are the vector of the displacement, velocity, and acceleration of tower structure, respectively; $m_{t}, c_{t}$, and $k_{t}$ are the mass, damping, and stiffness of the TMD, respectively; $x_{t}, \dot{x}_{t}$, and $\ddot{x}_{t}$ are the displacement, velocity and acceleration of the TMD, respectively; $E$ is the tuned mass damper located position vector.

Equations (3) can be written in a unified expression form

$$
\begin{gathered}
{\left[\begin{array}{ccc}
\mathbf{M}_{a a} & \mathbf{M}_{a b} & 0 \\
\mathbf{M}_{b a} & \mathbf{M}_{b b} & 0 \\
0 & m_{t} E^{T} & m_{t}
\end{array}\right]\left\{\begin{array}{l}
\ddot{\mathbf{x}}_{a} \\
\ddot{\mathbf{x}}_{b} \\
\ddot{x}_{t}
\end{array}\right\}+\left[\begin{array}{ccc}
\mathbf{C}_{a a} & \mathbf{C}_{a b} & 0 \\
\mathbf{C}_{b a} & \mathbf{C}_{b b} & -E c_{t} \\
0 & 0 & c_{t}
\end{array}\right]\left\{\begin{array}{l}
\dot{\mathbf{x}}_{a} \\
\dot{\mathbf{x}}_{b} \\
\dot{x}_{t}
\end{array}\right\}} \\
+\left[\begin{array}{ccc}
\mathbf{K}_{a a} & \mathbf{K}_{a b} & 0 \\
\mathbf{K}_{b a} & \mathbf{K}_{b b} & -E k_{t} \\
0 & 0 & k_{t}
\end{array}\right]\left\{\begin{array}{l}
\mathbf{x}_{a} \\
\mathbf{x}_{b} \\
x_{t}
\end{array}\right\}=\left\{\begin{array}{c}
P_{a} \\
0 \\
0
\end{array}\right\}
\end{gathered}
$$

where $\mathbf{M}_{a a}, \mathbf{C}_{a a}$, and $\mathbf{K}_{a a}$ are the $m \times m$ mass, damping, and stiffness matrices associated with the supported degrees of freedom, respectively; $\mathbf{M}_{b b}, \mathbf{C}_{b b}$, and $\mathbf{K}_{b b}$ are the $n \times n$ mass, damping, and stiffness matrices associated with the unconstrained degrees of freedom, respectively; $\mathbf{M}_{a b}, \mathbf{C}_{a b}$, and $\mathbf{K}_{a b}$ are the $m \times n$ coupling matrices associated with both sets of degrees of freedom; $\mathbf{P}_{a}$ is the $m$-vector of the reacting 
forces at the support degrees of freedom; $\ddot{\mathbf{x}}_{a}, \dot{\mathbf{x}}_{a}$, and $\mathbf{x}_{a}$ are the vector of the ground motion; $\ddot{\mathbf{x}}_{b}, \dot{\mathbf{x}}_{b}$, and $\mathbf{x}_{b}$ are the vector of the unconstrained degrees of freedom.

Based on the second and third rows of (4), the dynamic balance equation can be expressed as

$$
\begin{aligned}
& \mathbf{M}_{b a} \ddot{\mathbf{x}}_{a}+\mathbf{M}_{b b} \ddot{\mathbf{x}}_{b}+\mathbf{C}_{b a} \dot{\mathbf{x}}_{a}+\mathbf{C}_{b b} \dot{\mathbf{x}}_{b} \\
& \quad-E \mathbf{c}_{d} \dot{x}_{t}+\mathbf{K}_{b a} \mathbf{x}_{a}+\mathbf{K}_{b b} \mathbf{x}_{b}-E \mathbf{k}_{d} x_{t}=0, \\
& m_{t} E^{T} \ddot{x}_{b}+m_{t} \ddot{x}_{t}+c_{t} \dot{x}_{t}+k_{t} x_{t}=0 .
\end{aligned}
$$

Assuming that the mass matrix is diagonal and $\mathbf{C}_{a b}$ is neglected, (5) is reduced to

$$
\mathbf{M}_{b b} \ddot{\mathbf{x}}_{b}+\mathbf{C}_{b b} \dot{\mathbf{x}}_{b}+\mathbf{K}_{b b} \mathbf{x}_{b}-E\left(\mathbf{c}_{d} \dot{x}_{t}+\mathbf{k}_{d} x_{t}\right)=-\mathbf{K}_{b a} \mathbf{x}_{a} .
$$

Equation (6) can be extended to three components:

$$
\begin{aligned}
\mathbf{M}_{b b} \ddot{\mathbf{x}}_{b} & +\mathbf{C}_{b b} \dot{\mathbf{x}}_{b}+\mathbf{K}_{b b} \mathbf{x}_{b}-E\left(\mathbf{c}_{d} \dot{x}_{t}+\mathbf{k}_{d} x_{t}\right) \\
& =-\mathbf{K}_{b a}\left(x_{a}+y_{a}+z_{a}\right),
\end{aligned}
$$

where $x_{a}, y_{a}$, and $z_{a}$ are the input ground motion displacements in two horizontal and one vertical directions, respectively.

2.3. Calculation Formula of TMD. The tuned mass damper is constituted by mass block, spring, and damping. The mass block, spring, and damping can be derived as

$$
\begin{gathered}
m_{d}=\mu M, \\
k_{d}=m_{d} \omega^{2}, \\
c_{d}=2 m_{d} \omega^{2} \xi,
\end{gathered}
$$

where $M$ is the mass of the tower structure, $\mu$ is mass ratio, $\omega$ is the frequency of the tower structure, and $\xi$ is the damping ratio of the TMD. The optimal damping ratio is given in [12]

$$
\xi=\sqrt{\frac{3 \mu}{8(1+\mu)}} .
$$

\section{Modeling of Power Transmission Tower-Line System}

A finite-element computer program SAP2000 is selected to establish the model. A typical transmission tower such as the one shown in Figure 3 is considered in the study. The tower is $49.7 \mathrm{~m}$ high, and the weight of the tower is approximately $19 \mathrm{t}$. The structural members of the tower are made of angle steel with the elastic modulus of $206 \mathrm{GPa}$. The tower is modeled by 1412 space beam members and 575 nodes, and the connections of members are rigid, and the base points of the tower are assumed fixed. Figure 4 shows the transmission tower finite model. The frequencies of free vibration corresponding to the first three modes of the tower are found to be $1.71,1.93$, and $2.44 \mathrm{~Hz}$, respectively.

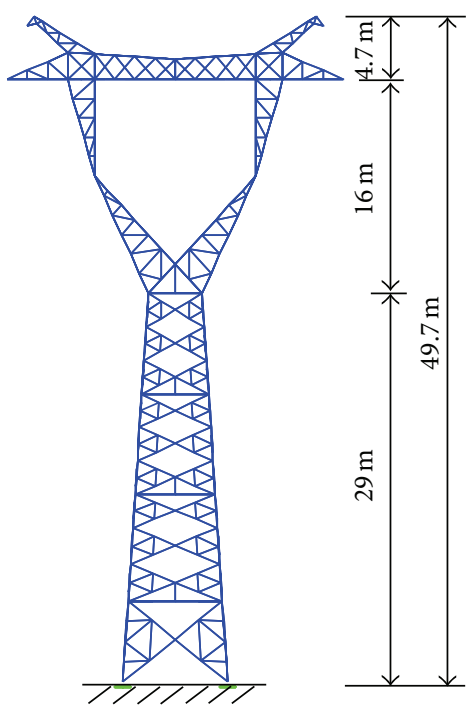

Figure 3: Transmission tower.

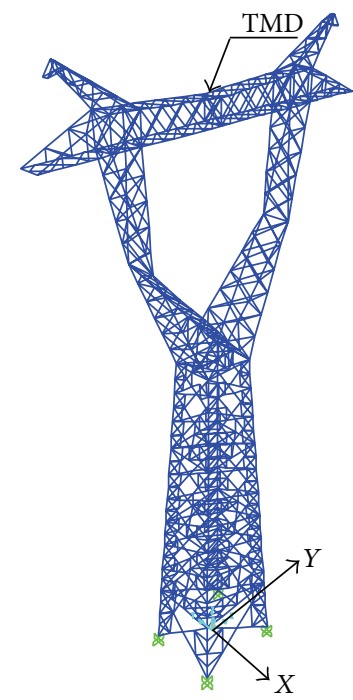

Figure 4: Transmission tower finite model.

Each transmission line is modeled by two-node isoparametric cable elements with three translational degrees of freedom at each node. The initial axial force and large deformation effect of cable are taken into consideration. Under self-weight, the cable spatial configuration is a catenary. Based on the coordinate system illustrated in Figure 5, the mathematical expression used to define the initial geometry of the cable profile is given in the following form [13]:

$$
z=\frac{H}{q}|\cosh (\alpha)-\cosh | \frac{2 \beta}{l}-\alpha||,
$$

where $\alpha=\sin h^{-1}|\beta(c / 1) / \sin (\beta)|+\beta, \beta=(q l / 2 H)$, in which $H$ represents initial horizontal tension which can be obtained from a preliminary static analysis, and $q$ denotes uniformly distributed gravity loads along the transmission line.

The types of transmission conductor and ground wire are LGJ-400/35 and LGJ-95/55, respectively. Conductor line and 
TABLE 1: Conductor line and ground line properties.

\begin{tabular}{lcc}
\hline Type & Conductor line & Ground line \\
\hline Transmission line & LGJ-400/35 & LGJ-95/55 \\
Outside diameter $(\mathrm{m})$ & $26.82 E-3$ & $16.00 E-3$ \\
Modulus $(\mathrm{GPa})$ & 65 & 105 \\
Transversal cross-section $\left(\mathrm{m}^{2}\right)$ & $425.24 E-6$ & $152.81 E-6$ \\
Mass per unit length $(\mathrm{Kg} / \mathrm{m})$ & 1.3490 & 0.6967 \\
Line expansion coefficient $\left(1 /{ }^{\circ} \mathrm{C}\right)$ & $2.05 E-005$ & $1.55 E-005$ \\
\hline
\end{tabular}

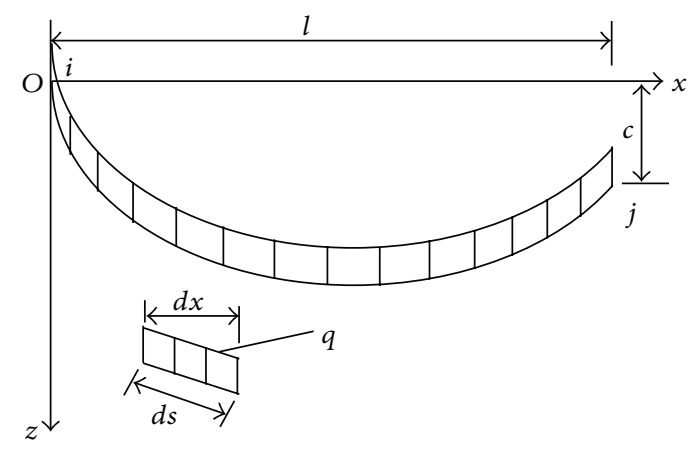

Figure 5: Coordinates of a single cable under self-weight.

ground wire properties are shown in Table 1. There are 20 transmission lines including 12 transmission conductors and 8 ground lines. As shown in Figure 6, the transmission towerline coupled system includes three towers $\left(1^{\#}\right.$ tower, $2^{\#}$ tower, and $3^{\#}$ tower) and four-span line (Span 1, Span 2, Span 3, and Span 4), and the side spans of the lines are hinged at the same height of middle tower [14]. The spans of adjacent towers are all $425 \mathrm{~m}$.

\section{Optimal Design of the System with TMD}

The transmission tower-line system shown in Figure 6 is used in the numerical simulation analysis. The damping ratio of the tower and line are assumed to be $2 \%$ and $1 \%$, respectively. The Newmark- $\beta$ method is applied in the numerical integration. The top node and along the height of middle transmission tower ( $2^{\#}$ tower) are selected as the object of the study. Three components of the 1940 Imperial Valley earthquake at El Centro site are used for time-history analysis, with peak ground motion scaled to $0.4 \mathrm{~g}$ along the $Y$-direction of system, and the other direction of seismic waves are adjusted according to corresponding proportion. The location of TMD on the tower can be seen in Figure 4. The reduction ratio is better when the location of TMD on the top of tower than other locations, so the reduction ratio about the location is not discussed.

In order to study the effect of control on the seismic responses of structure, vibration reduction ratio, $\delta$, can be defined as

$$
\delta=\frac{R_{0}-R_{1}}{R_{0}} \times 100 \%,
$$

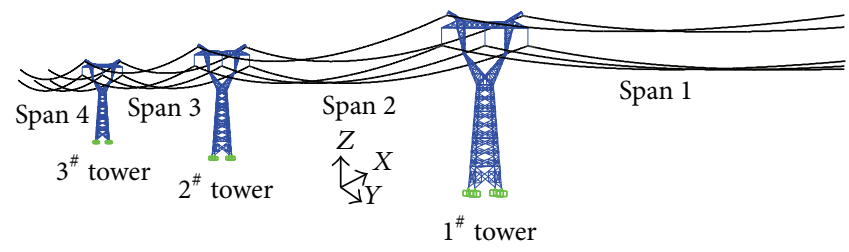

Figure 6: Three-dimensional finite model of the transmission tower-line coupled system.

where $R_{0}$ and $R_{1}$ are the responses of the tower without and with control, respectively.

4.1. Response of Single Tower and Tower-Line System with TMD. To compare the effect of TMD control on the response of single tower and transmission tower-line system, the single tower and tower-line system without and with TMD control are analyzed, respectively. The mass ratio of TMD is $2 \%$ in this section.

Figure 7(a) and Figure 8(a) show the top displacements in $X$-direction of the single tower and $2^{\#}$ tower of system, and their vibration reduction ratios are $34.5 \%$ and $21.3 \%$, respectively. The top displacements in $Y$-direction of the single tower and $2^{\#}$ tower of system are shown in Figure 7(b) and Figure $8(\mathrm{~b})$, and their vibration reduction ratios are $20.8 \%$ and $26.2 \%$, respectively. As shown in Figures 7 (c) and 8 (c), the axial forces along the height of the single tower and $2^{\#}$ tower of system are given, and their vibration reduction ratios are approximately $19.0 \%$ and $9.0 \%$, respectively.

The previous results show that the control effect of the displacement of the single tower is larger than that of $2^{\#}$ tower of system in $X$-direction, but the opposite results in $Y$ direction. The control effect of axial force of the single tower is significantly larger than that of $2^{\#}$ tower of system. Because of the coupled effect and flexible connection of the transmission towers and lines, the control effect of transmission tower-line system is different from that of the single tower. Therefore, the vibration control design of transmission tower should consider the effect of transmission lines.

4.2. Effect of Mass Ratio. In order to investigate the effect of mass ratio of TMD on the response of the system, ten different mass ratios are considered in the analysis, $0.01,0.015,0.02$, $0.025,0.03,0.04,0.05,0.06,0.07$, and 0.08 .

Vibration reduction ratios of $2^{\#}$ tower of system with different mass ratios are shown in Figure 9. It can be seen from Figure 9 that the vibration reduction effect can be improved according to increasing mass ratio, but there is an optimal mass ratio, after which adding more mass would slightly improve effect. The vibration reduction ratios of displacement and acceleration in $X$-direction increase significantly to $33.9 \%$ and $34.6 \%$ with mass ratio increasing until $4 \%$. The vibration reduction ratios of displacement and acceleration in $Y$-direction increase significantly to $35.9 \%$ and $31.7 \%$ with mass ratio increasing until $4 \%$. The 


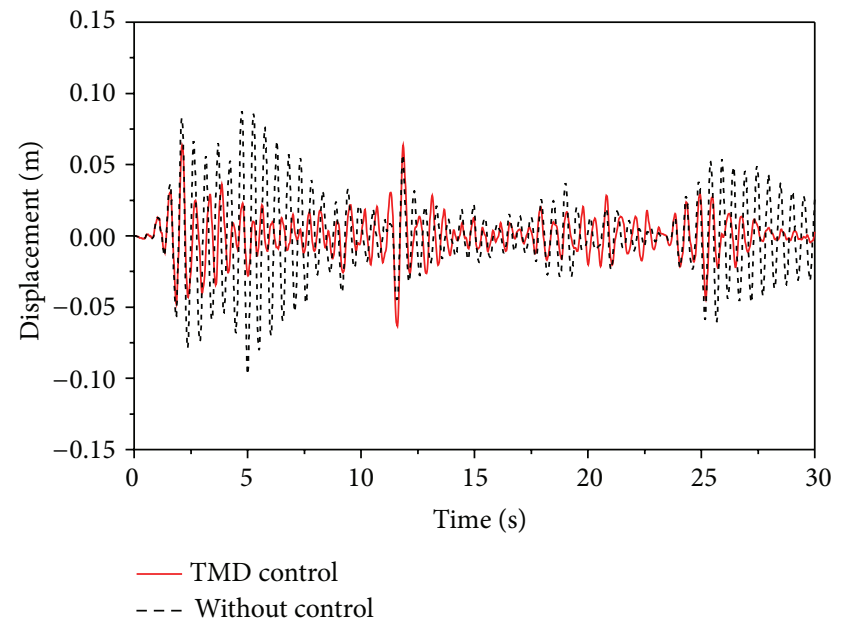

(a) The displacement in $X$ direction

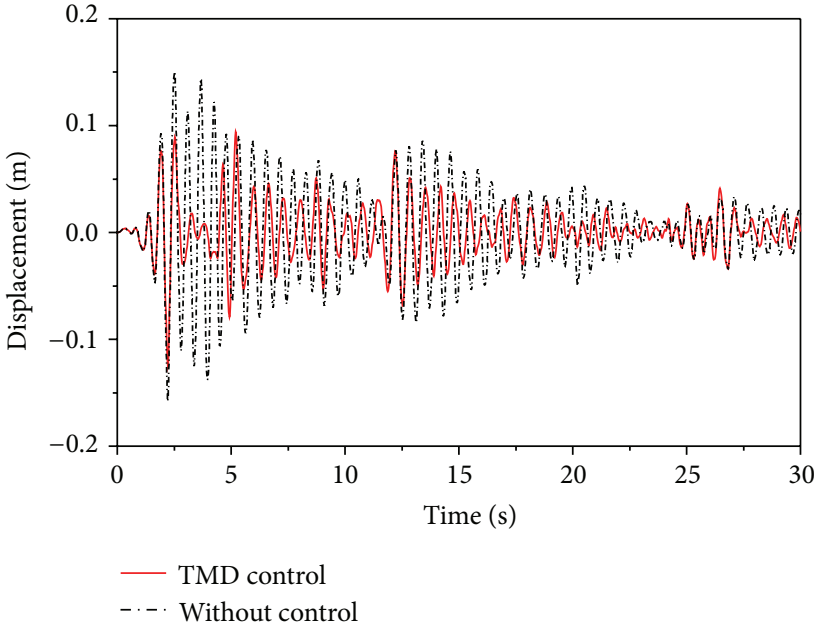

(b) The displacement in $Y$ direction

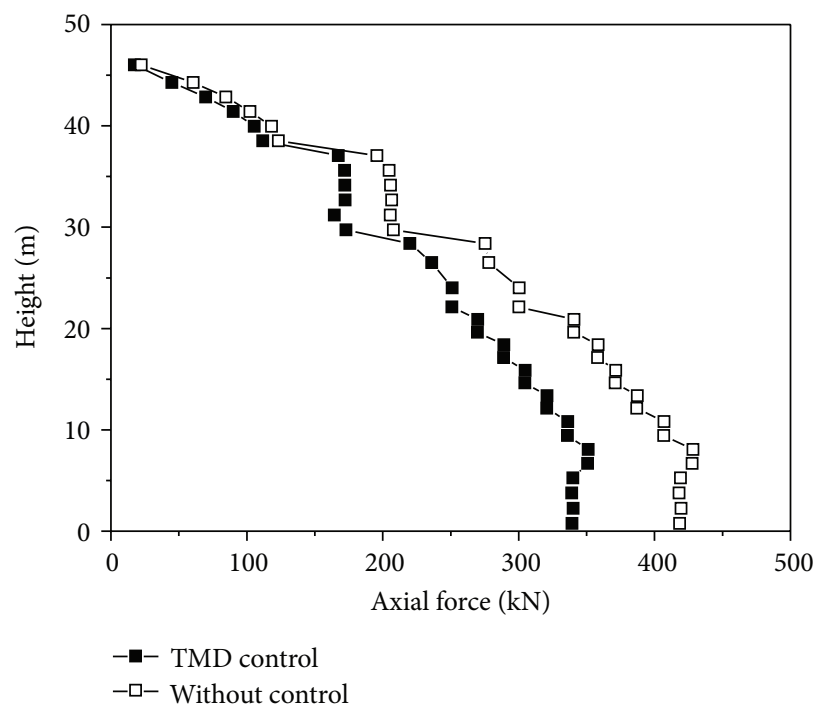

(c) Axial force

FIgURE 7: The response of single tower under El Centro wave excitation.

vibration reduction ratio of axial force increases significantly to $22 \%$ with mass ratio increasing until $4 \%$. Afterwards, the performance is improved to be less than $4 \%$ adding $1 \%$ more mass. Therefore, the optimal design of the mass ratio of TMD is $4 \%$.

4.3. Robustness Study. In order to study the robustness of TMD, the case where the ice loads are on the transmission tower and line is taken into consideration. The optimal design of the mass ratio of TMD is selected in this section. It is assumed that the whole transmission line is icing; the cover ice thickness is $30 \mathrm{~mm}$, and density of ice coating is $0.9 \mathrm{~g} / \mathrm{cm}^{3}$.

The displacement time histories of $2^{\#}$ tower of system with ice under El Centro wave excitation are shown in Figure 10. It is seen from Figure 10 that the vibration reduction ratios of $2^{\#}$ tower of system with ice in $X$ - and $Y$-directions are $33.8 \%$ and
$27.7 \%$, respectively. The mass and natural frequency of tower may be changed by ice load, so the vibration reduction ratio would be changed.

\section{Parameter Study}

Responses of the transmission tower-line system without and with TMD subjected to multicomponent multisupport ground motions are analyzed. The HHT method is applied in the numerical integration. Based on the above research, the optimal design of the mass ratio of TMD is selected.

5.1. Simulation of Multicomponent Multisupport Ground Motions. The ground motion cross-power spectral density function of spatial ground motions at points $i$ and $j$ on ground surface can be written as

$$
S_{i j}(\omega)=S_{g}(\omega) \gamma_{i j}\left(\omega, d_{i j}\right),
$$




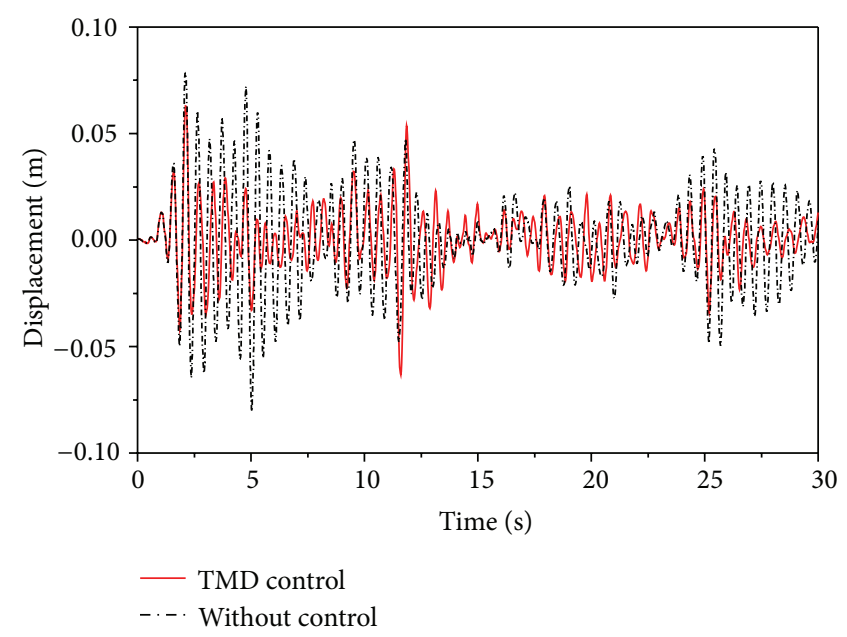

(a) The displacement in $X$-direction

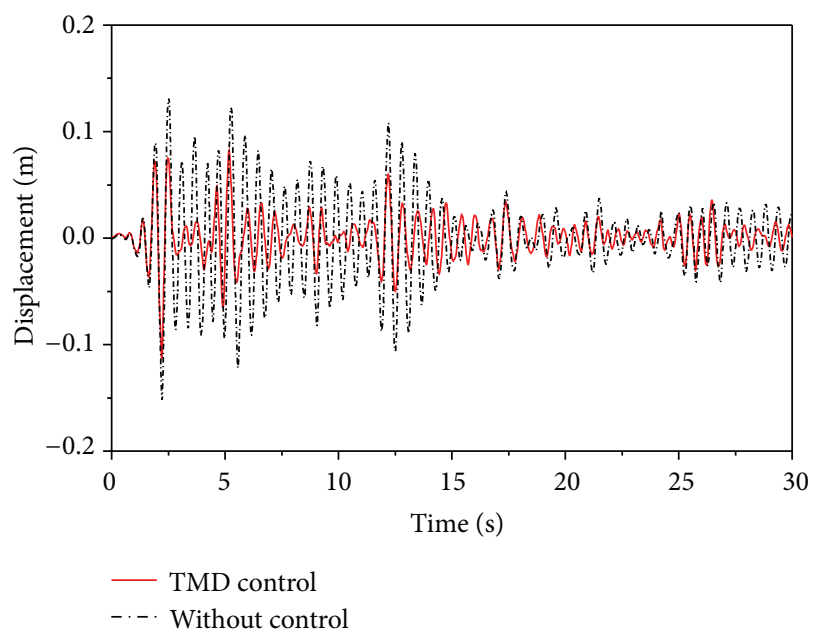

(b) The displacement in $Y$-direction

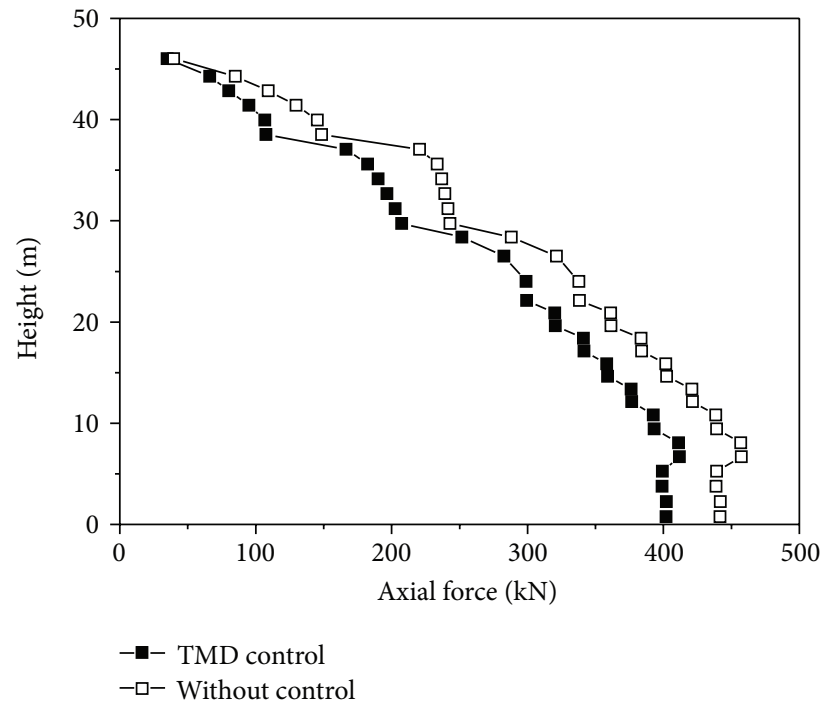

(c) Axial force

FIgURE 8: The response of $2^{\#}$ tower of system under El Centro wave excitation.

where

$$
\begin{aligned}
S_{g}(\omega)= & \frac{\omega_{g}^{4}+4 \xi_{g}^{2} \omega_{g}^{2} \omega^{2}}{\left(\omega_{g}^{2}-\omega^{2}\right)^{2}+4 \xi_{g}^{2} \omega_{g}^{2} \omega^{2}} \\
& \cdot \frac{\omega^{4}}{\left(\omega_{f}^{2}-\omega^{2}\right)^{2}+4 \xi_{f}^{2} \omega_{f}^{2} \omega^{2}} S_{0}
\end{aligned}
$$

is a filtered Tajimi-Kanai power spectral density function [15], in which $S_{0}$ is a scale factor depending on the ground motion intensity, $\omega_{g}$ and $\xi_{g}$ are the predominant frequency and damping ratio of the first filter, and $\omega_{f}$ and $\xi_{f}$ are those of the second filter. Consider the following:

$$
\gamma_{i j}\left(\omega, d_{i j}\right)=\left|\gamma_{i j}\left(\omega, d_{i j}\right)\right| e^{-i \omega d_{i j} / v}
$$

is an empirical coherency function. In the present paper, the coherency loss function at points $i$ and $j$ was derived from SMART-1 array data by Hao et al. [16]. The parameters were obtained by processing recorded motions during event 45 at the SMART-1 array. In order to compare, different degrees of coherency loss are selected according to reference [17].

According to Penzien and Watabe's research [18], the three components of ground motions along a set of principal axes are uncorrelated. In this study, the three components of the ground motion are assumed to be directed along the principal axes.

In this study, the transmission tower-line system is assumed to be located in the Chinese Seismic Intensity Zone 9 with peak longitudinal ground acceleration $0.4 \mathrm{~g}$ and locate in the medium firm soil. The intensities of the transverse component and vertical component, as stated in the code, are 0.85 and 0.65 times of the longitudinal component. Based on 


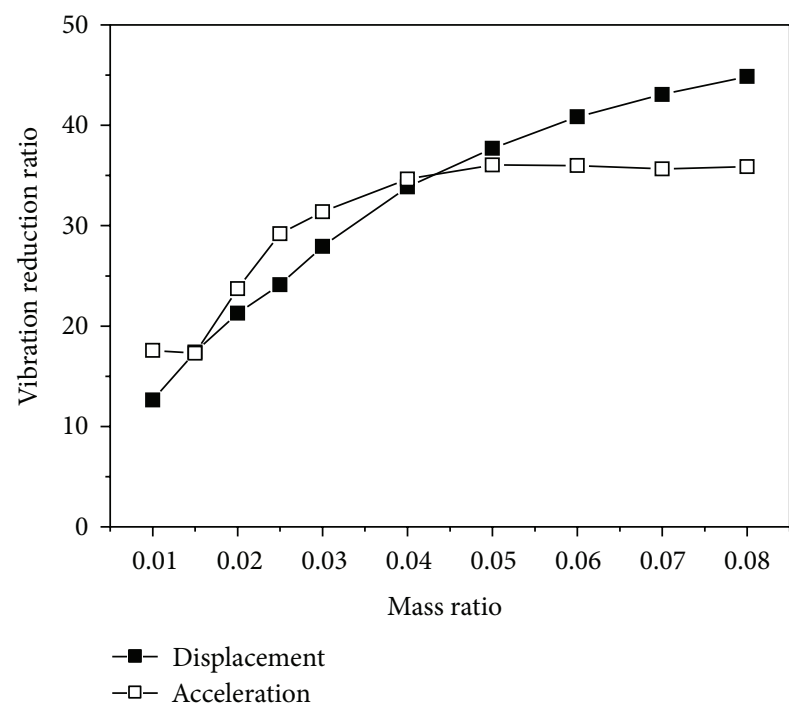

(a) The vibration reduction ratio in $X$-direction

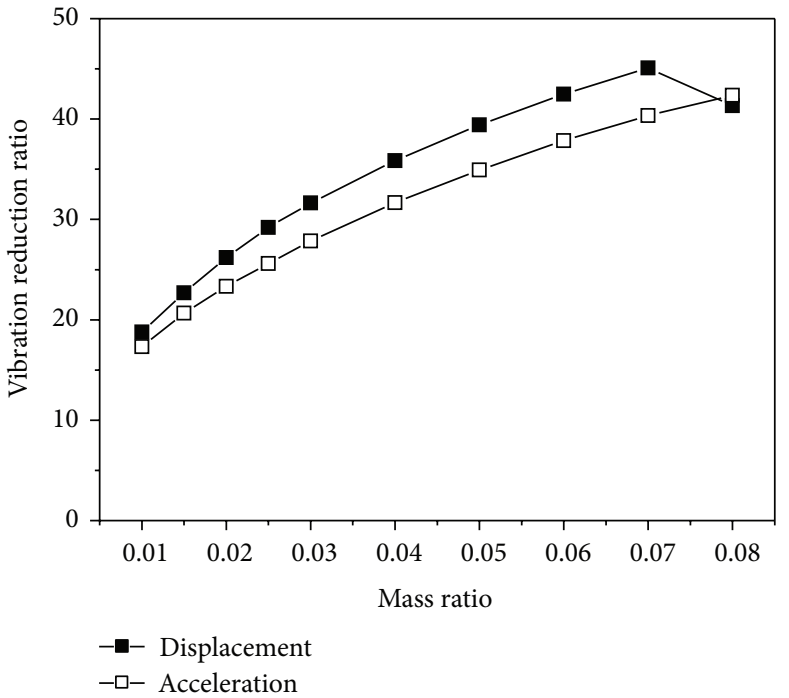

(b) The vibration reduction ratio in $Y$-direction

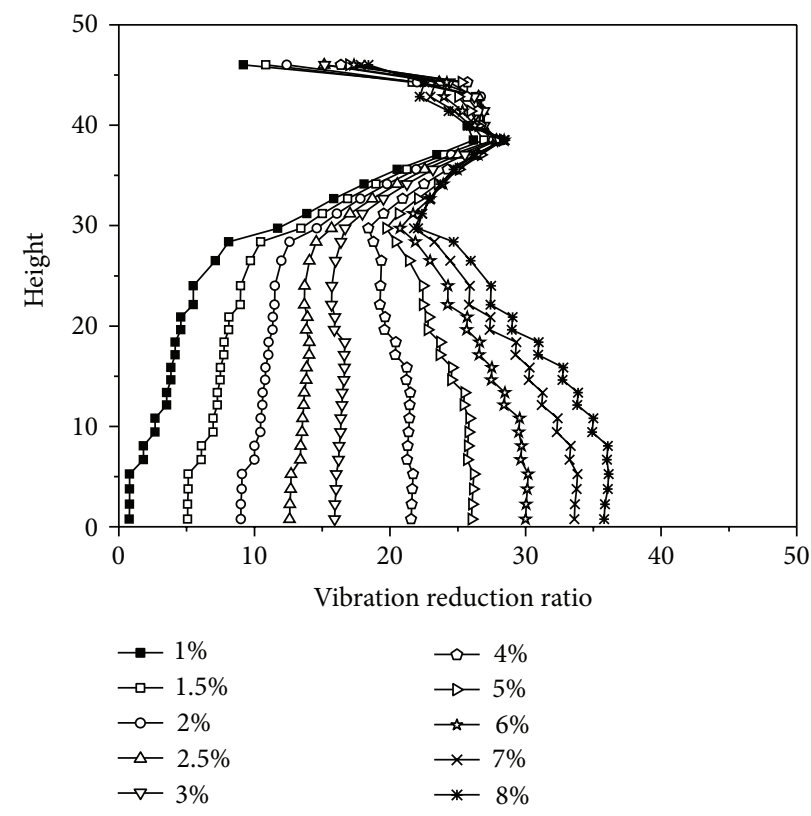

(c) Axial force

FIGURE 9: Vibration reduction ratios of $2^{\#}$ tower of system with different mass ratio.

the reference method [14], the multi-component and multisupport seismic can be generated. Figure 11 shows multicomponent multi-support ground motions time histories.

5.2. Effect of Wave Travel. To investigate the effect of wave travel on the response of the system with TMD, six different velocities of wave propagation are considered in the analysis, uniform (Case 1), $1000 \mathrm{~m} / \mathrm{s}$ (Case 2), $1500 \mathrm{~m} / \mathrm{s}$ (Case 3), $2000 \mathrm{~m} / \mathrm{s}$ (Case 4), and infinite (Case 5). The case of uniform ground motion at all supports corresponds to a wave propagating with infinite velocity, and the case of infinite ground motion only considers the effect of coherency loss. In all these cases, the coherency loss and soil condition of ground motion are assumed to be highly correlated and the medium firm, respectively.

Figure 12 shows the vibration reduction ratios of $2^{\#}$ tower of system under different wave travel excitations. It can be seen from Figure 12 that the vibration reduction effect can be changed greatly under different wave travel excitations, especially for the vibration reduction ratios of displacement in $X$ direction. The response of displacement in $X$-direction with control is larger than that without control when the velocity is $1500 \mathrm{~m} / \mathrm{s}$, but the other results with control are smaller than that without control. When the apparent velocity is $1000 \mathrm{~m} / \mathrm{s}$, the vibration reduction ratios of displacement and acceleration in $Y$-direction are larger than other cases. The 


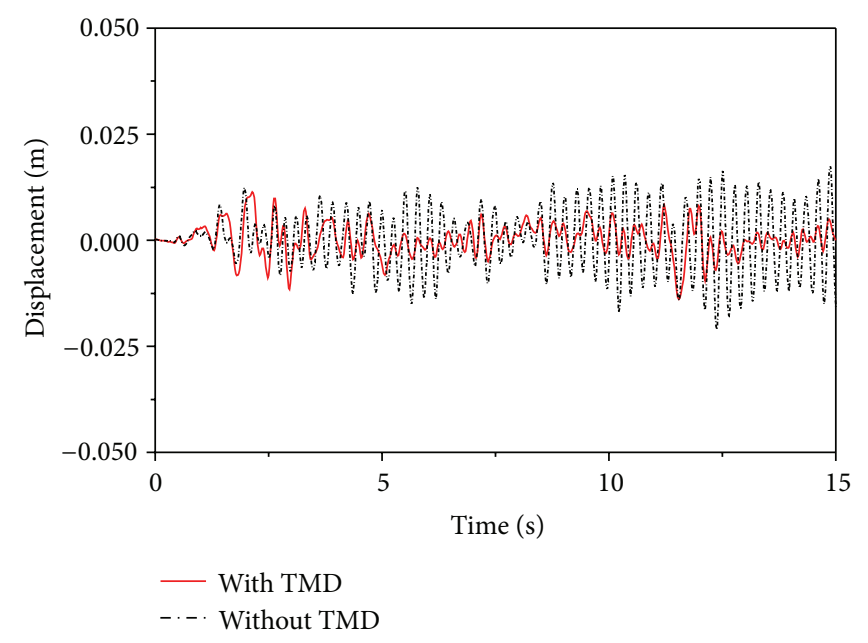

(a) The displacement in $X$-direction

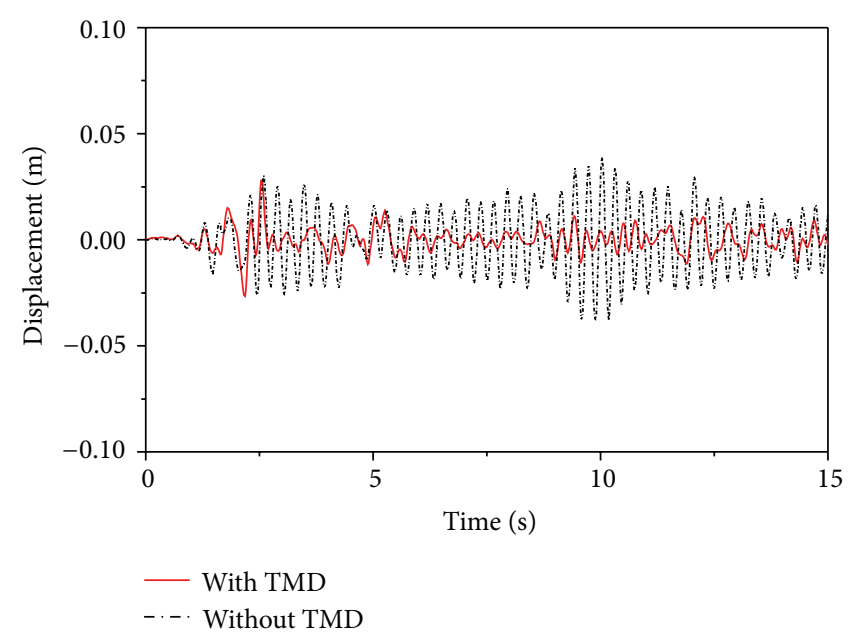

(b) The displacement in $Y$-direction

FIgURE 10: Displacement time histories of $2^{\#}$ tower of system with ice under El Centro wave excitation.

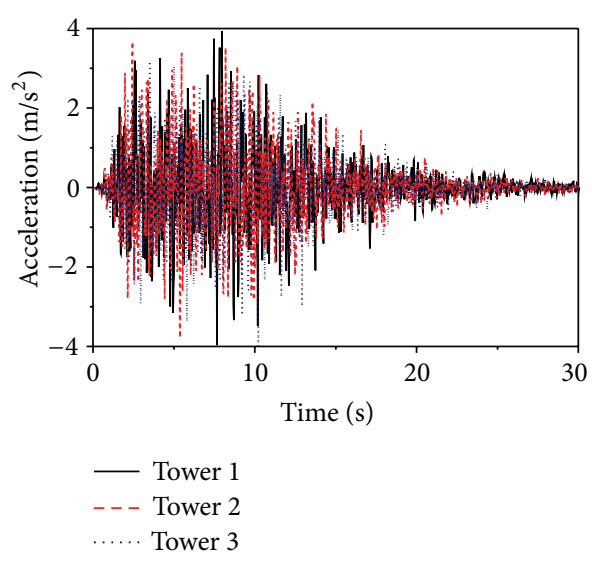

(a) $Y$-direction

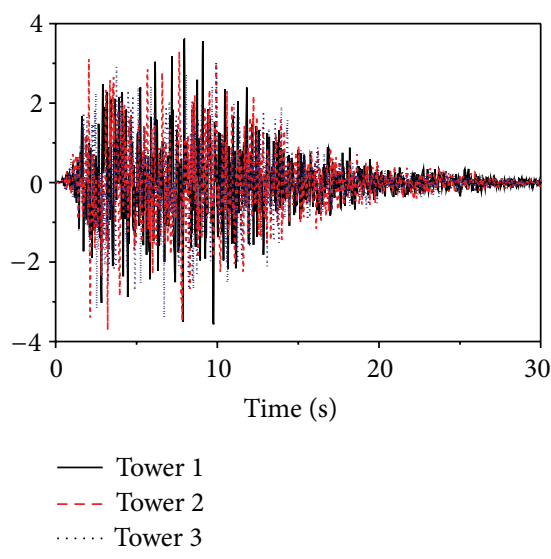

(b) $X$-direction

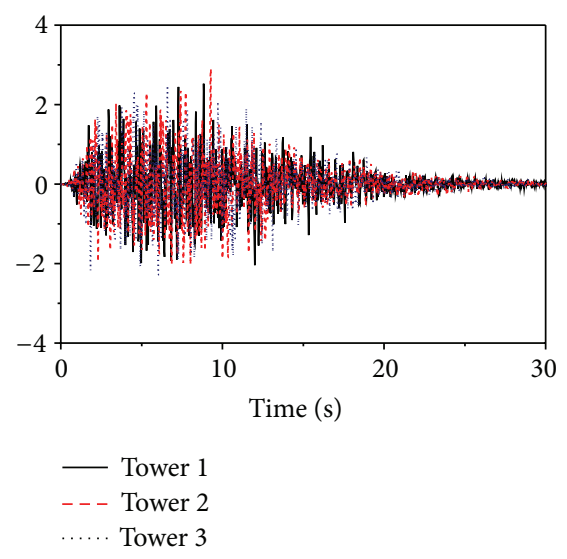

(c) Z-direction

FIGURE 11: Seismic waves of every transmission tower supports in three-dimensional direction.

vibration reduction ratio of axial force at bottom of system under uniform excitation is smaller than those considering the effect of wave travel.

According to the variations of the vibration reduction ratios of system considering the change of traveling wave velocity, the traveling wave velocity has a significant influence on the vibration reduction ratio of the system. Therefore, the traveling wave velocity cannot be ignored for the vibration reduction ratios of transmission tower-line system.

5.3. Effect of Coherency Loss. To study the influence of coherency loss on the response of the system with TMD, uniform (Case 1), completely correlated (Case 2), highly correlated (Case 3), and intermediately correlated (Case 4) ground motions are considered. In all these cases, the apparent velocity and soil condition of ground motion are assumed to be $1000 \mathrm{~m} / \mathrm{s}$ and the medium firm, respectively.

Figure 13 shows the vibration reduction ratios of $2^{\#}$ tower of the system under different degrees of coherency loss.
The vibration reduction ratios of the system are affected significantly by the change of coherency loss. The vibration reduction ratios of acceleration in $X$ displacement of the system have a tendency of increasing with the degrees of coherency loss decreasing, but the displacement has an opposite tendency. The vibration reduction ratios of displacement and acceleration in $Y$ displacement are larger than other cases when the coherency loss is highly correlated. The vibration reduction ratios of axial force of the system have a tendency of decreasing with the degrees of coherency loss decreasing.

The variations of the vibration reduction ratios of the system considering the change of coherency loss can be obtained from above analyses. To obtain a representative analysis, the degrees of coherency of spatial ground motions should be evaluated.

5.4. Effect of Site Condition. In order to research the effect of local site on the response of the system with TMD, uniform (Case 1), MF-MF-MF (Case 2), MF-F-F (Case 3), MF-MS-MS 


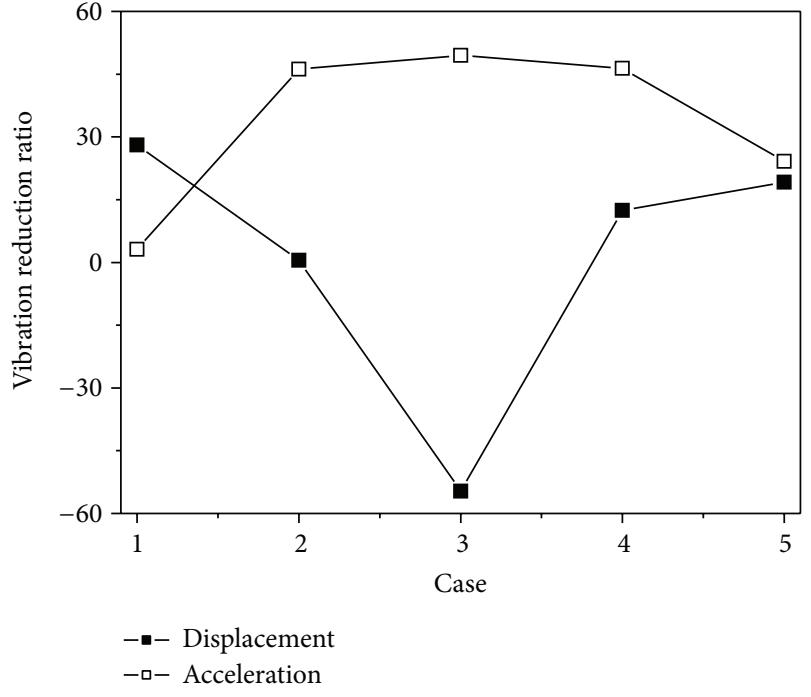

(a) The vibration reduction ratio in $X$-direction

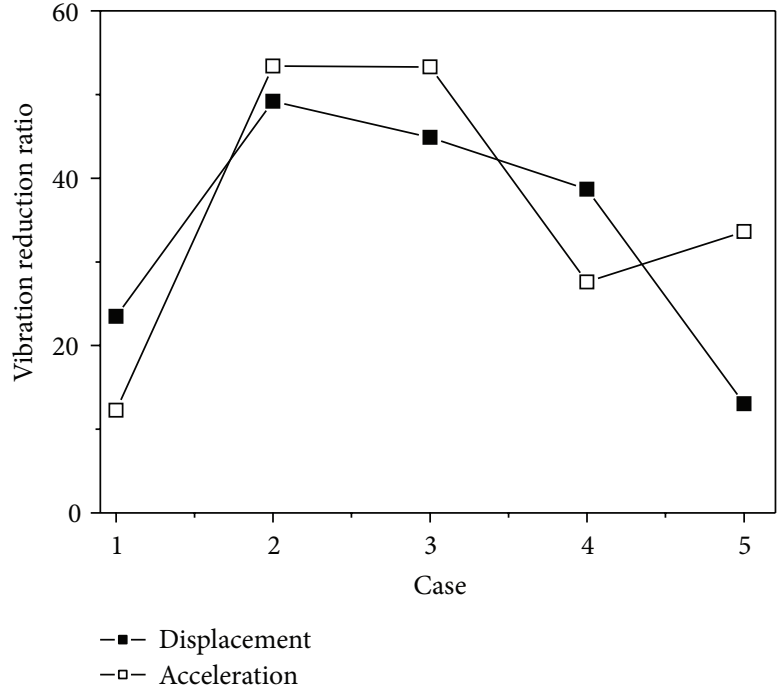

(b) The vibration reduction ratio in $Y$-direction

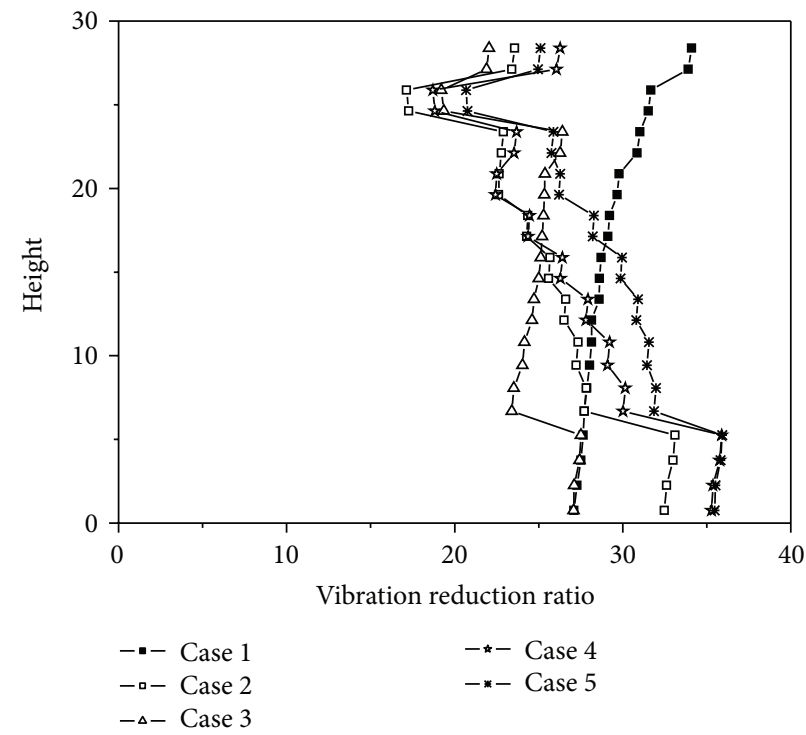

(c) Axial force

FIGURE 12: Vibration reduction ratios of $2^{\#}$ tower of system under different wave travel excitations.

(Case 4), and MF-S-S (Case 5) are considered. F, MF, MS, and $\mathrm{S}$ are denoted as firm, medium firm, medium soft, and soft soil. In all these cases, the apparent velocity and coherency of ground motion are assumed to be $1000 \mathrm{~m} / \mathrm{s}$ and highly correlated, respectively.

Figure 14 shows the vibration reduction ratios of $2^{\#}$ tower of system under different site conditions. The responses of displacements of system in $X$-direction with control are larger than those without control when considering the different local site conditions, but the acceleration has opposite results. The vibration reduction ratios of displacement and acceleration in $Y$-direction have the same variations, and the vibration reduction ratio is smaller than other cases when local site is MF-F-F. The vibration reduction ratio of axial force of system under MF-MS-MS site conditions excitation is larger than other cases.
The above results demonstrate that the site condition has a great influence on the vibration reduction ratios of system. Therefore, it is necessary to consider the local site of ground motion.

\section{Conclusions}

The seismic control of the transmission tower-line system under multi-component has been investigated in this paper. The optimal design of the system with TMD is investigated. The parameters studied include the effect of wave passage, coherency loss and different local site. Based on the numerical results and analysis, the following conclusions are drawn.

(1) The control effect of transmission tower-line system is different from the single tower, so the vibration 


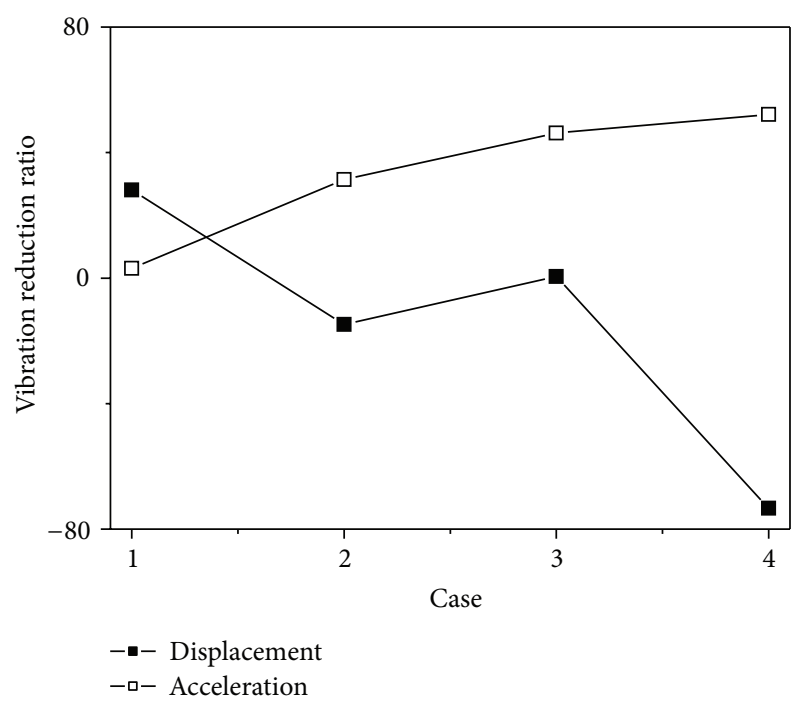

(a) The vibration reduction ratio in $X$-direction

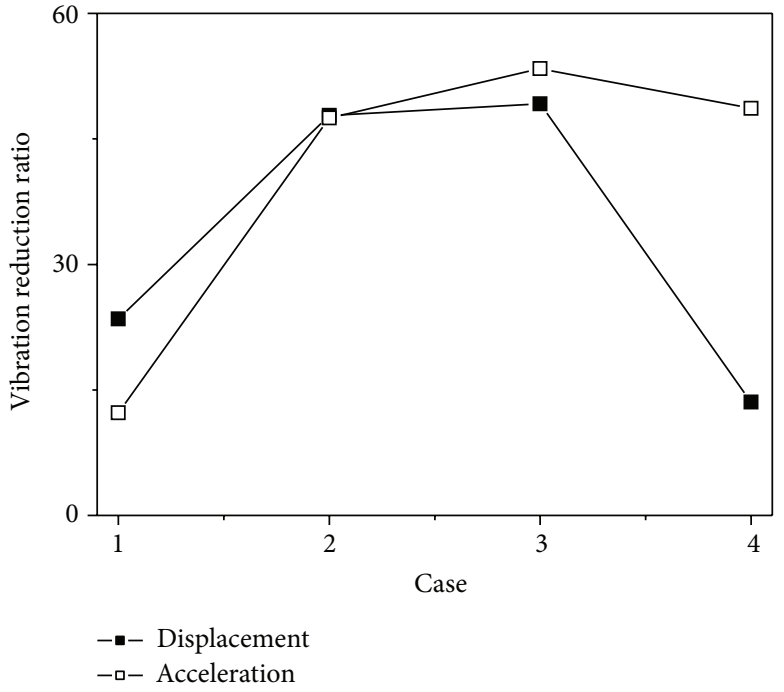

(b) The vibration reduction ratio in $Y$-direction

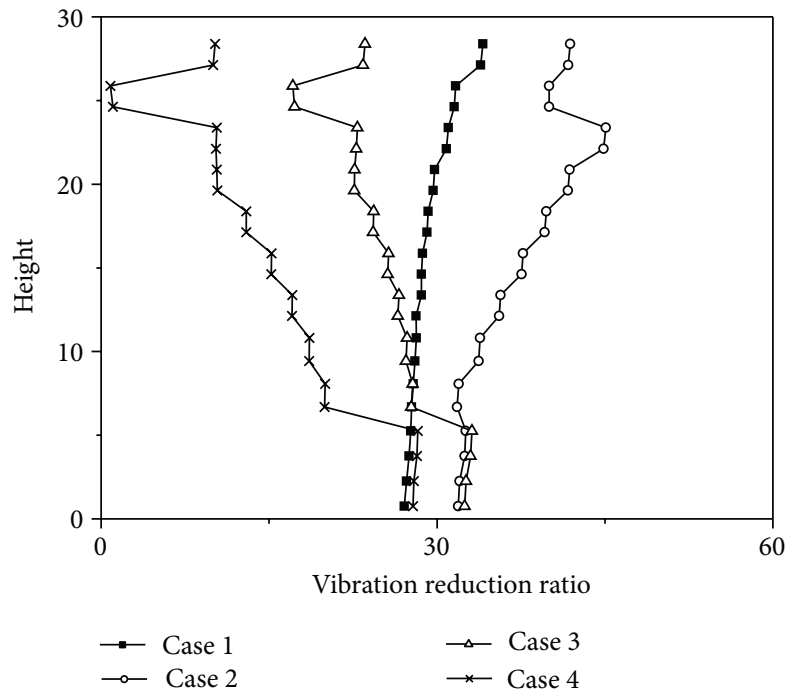

(c) Axial force

FIGURE 13: Vibration reduction ratios of $2^{\#}$ tower of system under different degrees of coherency loss.

control design of transmission tower should consider the effect of transmission lines.

(2) According to different mass ratio, the optimal design of the transmission tower-line system with TMD could be obtained.

(3) The mass and natural frequency of tower may be changed by ice load, so the vibration reduction ratio would be changed.

(4) The traveling wave velocity has a significant influence on the vibration reduction ratio of the system, and the traveling wave velocity can not be ignored for the vibration reduction ratios of transmission tower-line system
(5) To obtain a representative analysis, the degrees of coherency of spatial ground motions should be evaluated.

(6) The site condition has a great influence on the vibration reduction ratios of system, and it is necessary to consider the local site of ground motion.

This study demonstrates that the multi-component multisupport seismic excitations are very important to power transmission tower-line system. Therefore, more studies are deemed necessary to further investigate the multi-component multi-support ground motions effects on responses of these systems with control. 


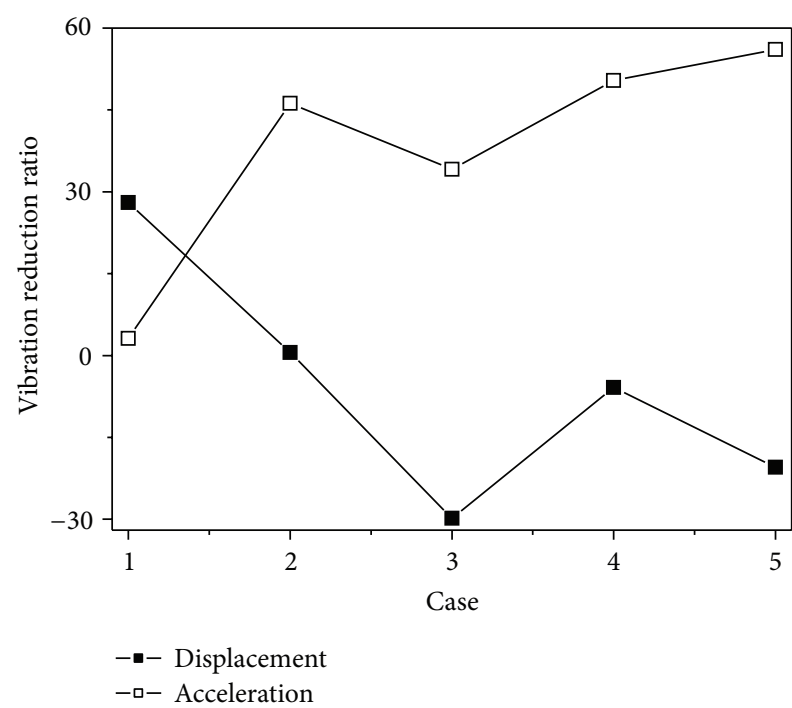

(a) The vibration reduction ratio in $X$-direction

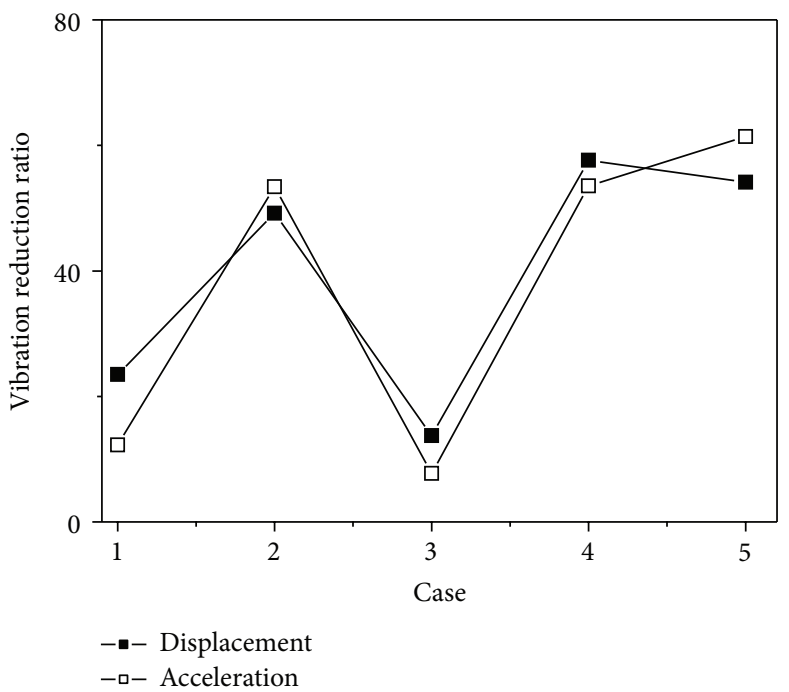

(b) The vibration reduction ratio in $Y$-direction

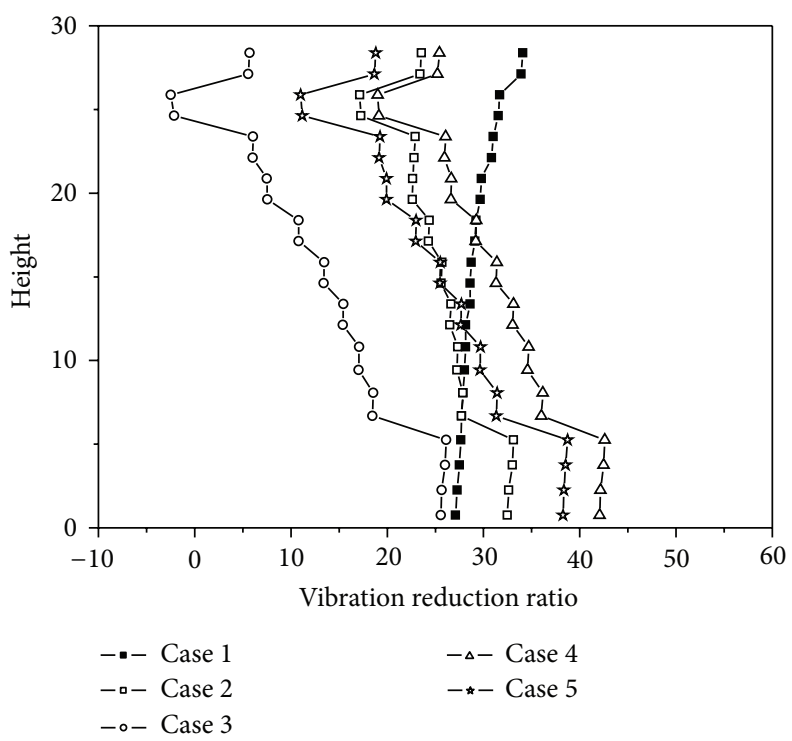

(c) Axial force

FIGURE 14: Vibration reduction ratios of $2^{\#}$ tower of system under different site conditions.

\section{Acknowledgments}

This work is supported by the National Natural Science Foundation of China under Grant no. 51208285, China Postdoctoral Science Foundation funded project under Grant no. 2012M521338, and Independent Innovation Foundation of Shandong University of China under Grant no. 2011GN051. The supports for this research are greatly appreciated.

\section{References}

[1] H. Li, W. Shi, G. Wang, and L. Jia, "Simplified models and experimental verification for coupled transmission tower-line system to seismic excitations," Journal of Sound and Vibration, vol. 286, no. 3, pp. 569-585, 2005.
[2] Q. Xie and J. Li, "Current situation of natural disaster in electric power system and counterm easures," Journal of Natural Disasters, vol. 15, no. 4, pp. 126-131, 2006 (Chinese).

[3] M. Shinozuka, "The Hanshin-Awaji earthquake of January 17, 1995 performance of life lines," Report NCEER-95-0015, NCEER, Alachua, Fla, USA, 1995.

[4] R. Yin, D. Li, G. Liu, and T. Zhai, "Seismic damage and analysis of power transmissions towers," World Information on Earthquake Engineering, vol. 21, no. 1, pp. 51-54, 2005 (Chinese).

[5] D. Zhang, W. Zhao, and M. Liu, "Analysis on seismic disaster damage cases and their causes of electric power equipment in 5. 12 Wenchuan earthquake," Journal of Nanjing University of Technology, vol. 31, no. 1, pp. 44-48, 2009 (Chinese).

[6] R. C. Battista, R. S. Rodrigues, and M. S. Pfeil, "Dynamic behavior and stability of transmission line towers under wind forces," 
Journal of Wind Engineering and Industrial Aerodynamics, vol. 91, no. 8, pp. 1051-1067, 2003.

[7] B. Huang and J. Tang, "Wind-induced vibration control of long span transmission tower," Control of Noise and Vibration, no. 5, pp. 2-5, 1997 (Chinese).

[8] Y. Chen and G. Tang, "Vibration control on tower for long span transmission lines," Special Structure, vol. 17, no. 3, pp. 43-46, 2000 (Chinese).

[9] H. Deng, S. Zhu, Y. Chen, and Z. Wang, "Study on windinduced vibration control of long span transmission line system," Journal of Building Structures, vol. 18, no. 4, pp. 60-65, 2003 (Chinese).

[10] G. Liu and H. Li, "Analysis and optimization control of wind-induced dynamic response for high-voltage transmission tower-line system," Proceedings of the Chinese Society of Electrical Engineering, vol. 28, no. 19, pp. 131-137, 2008 (Chinese).

[11] J. P. D. Hartog, Mechanical Vibrations, Mcgraw-Hill, New York, NY, USA, 1956

[12] R. Rana and T. T. Soong, "Parametric study and simplified design of tuned mass dampers," Engineering Structures, vol. 20, no. 3, pp. 193-204, 1998.

[13] S. Z. Shen, C. B. Xu, and C. Zhao, Design of Suspension Structure, China Architecture and Building Press, Beijing, China, 1997, (Chinese).

[14] L. Tian, H. Li, and G. Liu, "Seismic response of power transmission tower-line system subjected to spatially varying ground motions," Mathematical Problems in Engineering, vol. 2010, Article ID 587317, 20 pages, 2010.

[15] R. W. Clough and J. Penzien, Dynamics of Structures, McGrawHill, New York, NY, USA, 1975.

[16] H. Hao, C. S. Oliveira, and J. Penzien, "Multiple-station ground motion processing and simulation based on SMART-1 array data," Nuclear Engineering and Design, vol. 111, no. 3, pp. 1325$1345,1989$.

[17] K. Bi, H. Hao, and N. Chouw, "Required separation distance between decks and at abutments of a bridge crossing a canyon site to avoid seismic pounding," Earthquake Engineering and Structural Dynamics, vol. 39, no. 3, pp. 303-323, 2009.

[18] J. Penzien and M. Watabe, "Characteristics of 3-dimensional earthquake ground motions," Earthquake Engineering and Structural Dynamics, vol. 4, pp. 365-373, 1975. 


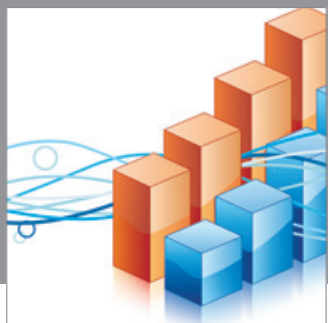

Advances in

Operations Research

mansans

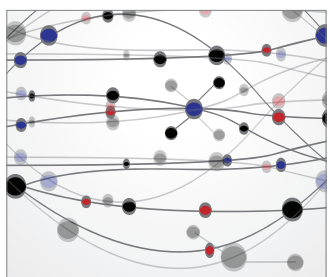

The Scientific World Journal
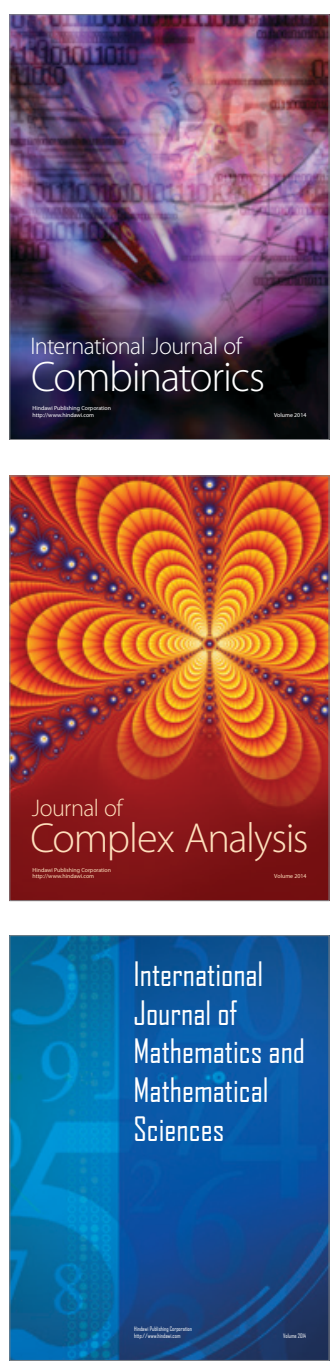
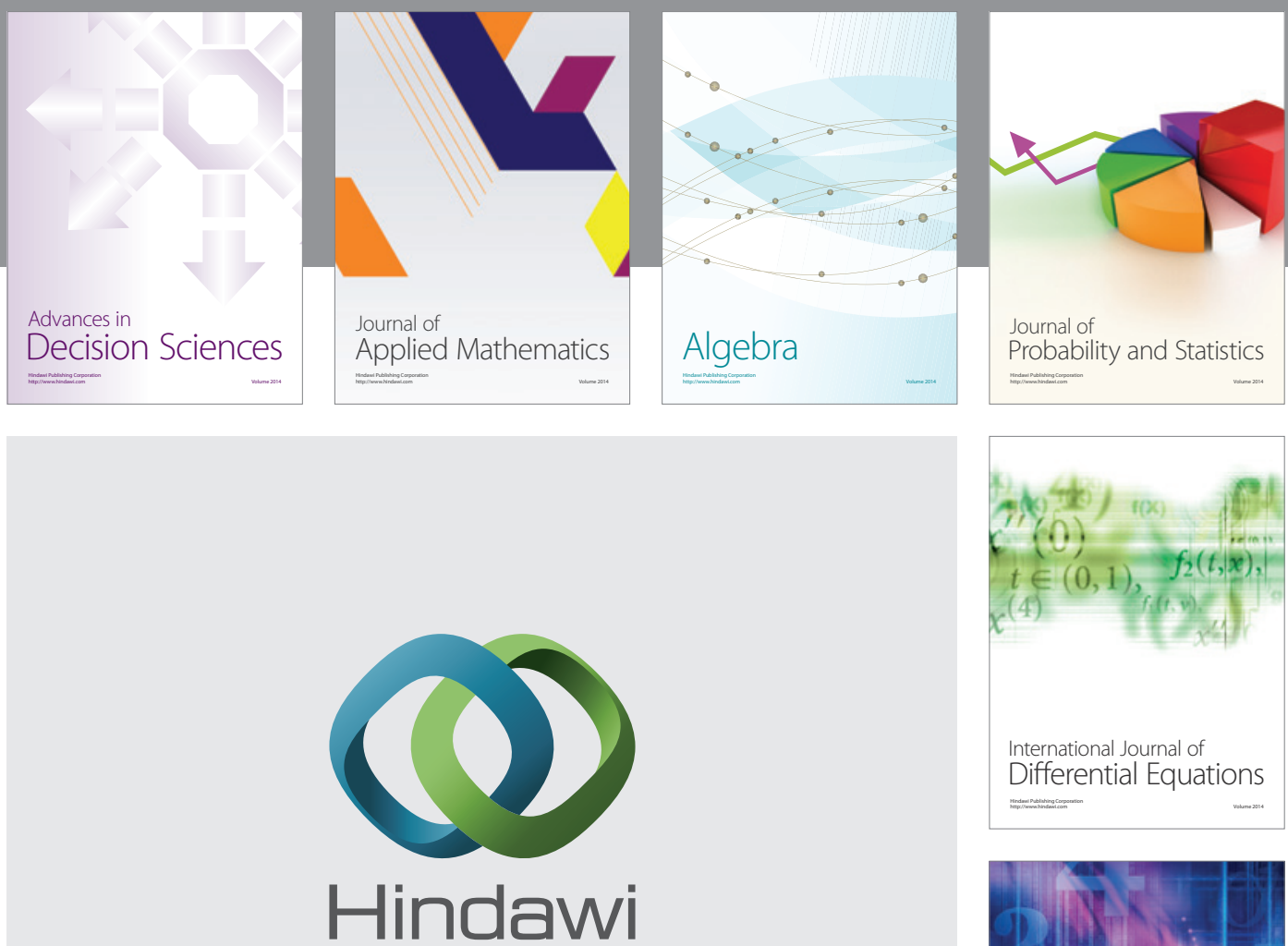

Submit your manuscripts at http://www.hindawi.com
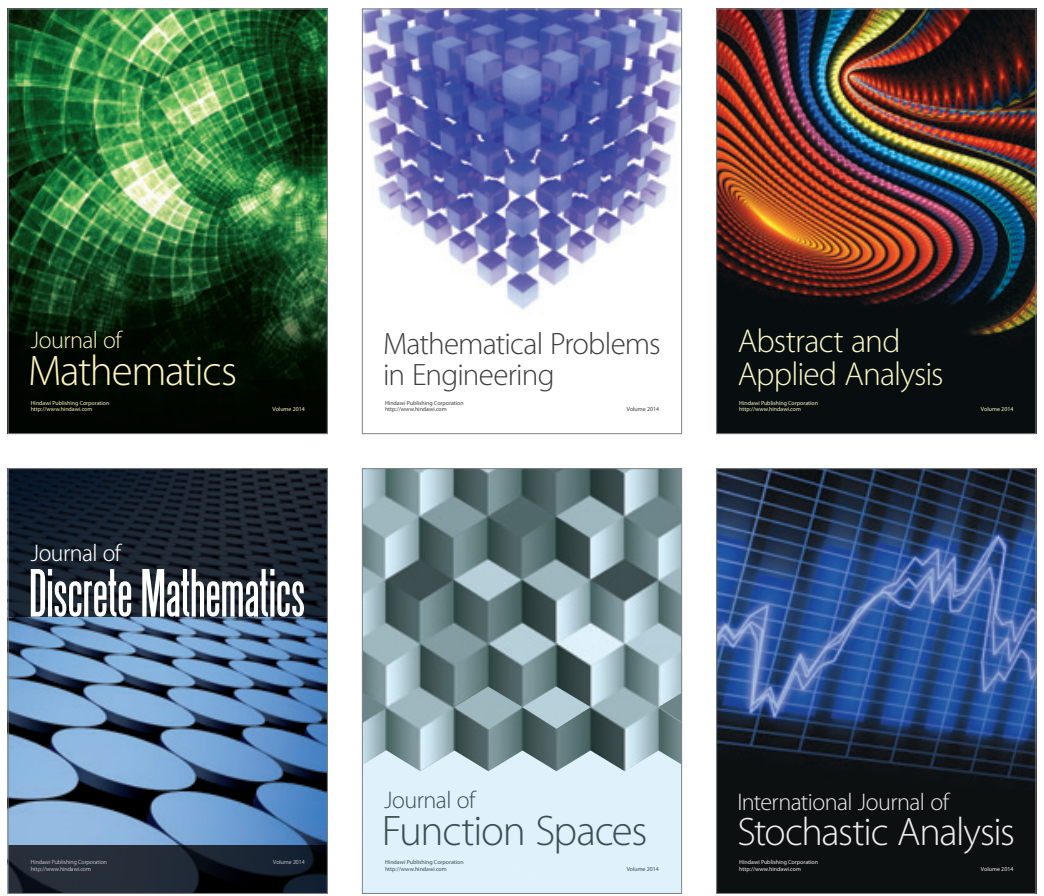

Journal of

Function Spaces

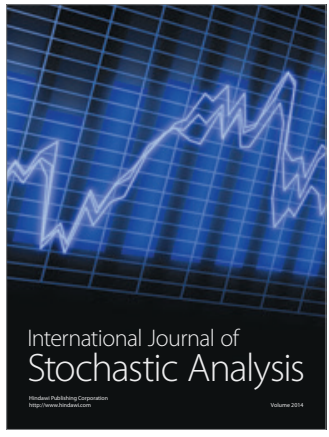

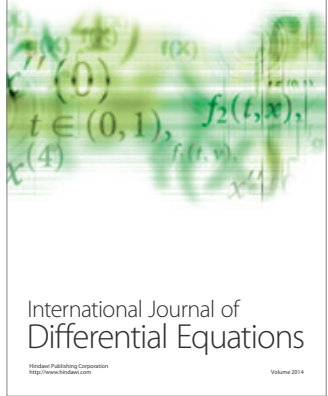
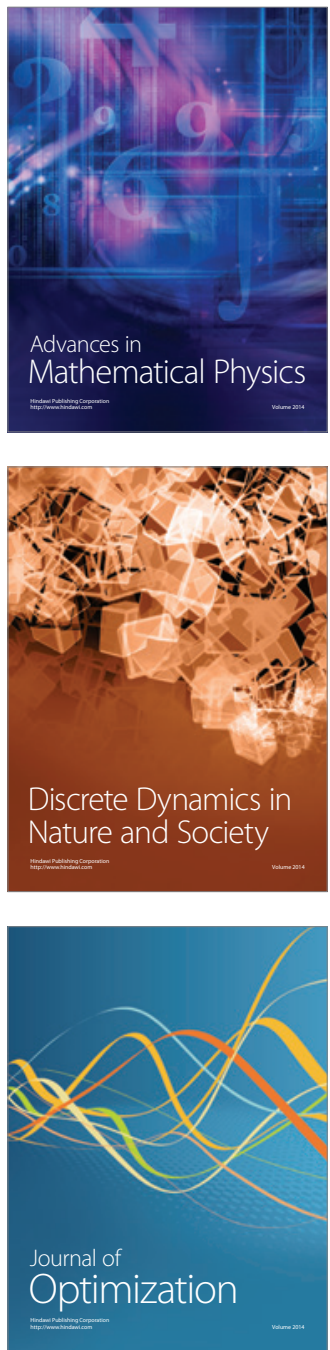